Article

\title{
Optimization of Purification, Identification and Evaluation of the in Vitro Antitumor Activity of Polyphenols from Pinus Koraiensis Pinecones
}

\author{
Juanjuan Yi ${ }^{1}$, Zhenyu Wang ${ }^{1,2, *}$, Haina Bai ${ }^{1}$, Xiaojin Yu ${ }^{3}$, Jing Jing ${ }^{1}$ and Lili Zuo ${ }^{4}$ \\ 1 Harbin Institute of Technology, 73 Huanghe Road, Nangang District, Harbin 150090, China \\ 2 Northeast Forestry University, 26 Hexing Road, Xiangfang District, Harbin 150040, China \\ 3 Heilongjiang University of Chinese Medicine, 24 Heping Road, Xiangfang District, \\ Harbin 150040, China \\ 4 Jilin Medical College, 5 Jilin street, Jilin 132013, China \\ * Author to whom correspondence should be addressed; E-Mail: wangzhenyu13001@163.com or \\ wzy219001@hit.edu.cn; Tel./Fax: +86-451-8628-2909.
}

Academic Editor: Jean Jacques Vanden Eynde

Received: 6 February 2015 / Accepted: 2 June 2015 / Published: 5 June 2015

\begin{abstract}
In this study, an efficient purification method for the polyphenols of Pinus koraiensis pinecone (PPP) has been developed. AB-8 resin was verified to offer good adsorption and desorption ratio for PPP. Response surface methodology (RSM) indicated that the optimized purification parameters for PPP were $1.70 \mathrm{mg}$ GAE/mL phenolic sample concentration, $22.00 \mathrm{~mL}$ sample volume, and $63.00 \%$ ethanol concentration. Under these conditions, the experimental purity of PPP was $27.93 \pm 0.14 \%(n=3)$, which matched well with the predicted purity of $28.17 \%$. Next, the antiproliferative effects of PPP on seven cancer cell lines, including A375 (human skin melanoma cancer cell line), A549 (human lung cancer cell line), SH-SY5Y (human neuroblastoma cell line), LOVO (human colon cancer stem cell line), MCF-7 (human breast cancer cell line), HeLa (human cervical cancer line), and HT29 (human colon cancer line), were examined by MTT assays. The results indicated that PPP had the highest capacity for inhibiting LOVO cells growth with an EC50 value of $0.317 \pm 0.0476 \mathrm{mg} / \mathrm{mL}$. Finally, Ultra-high performance liquid chromatography- tandem mass spectrometry (UPLC-MS) was used to tentatively identify twenty-four peaks in the purified PPP, of which five representative peaks were identified as catechin, methyl quercetin, $o$-vanillin, luteolin and coronaric acid. Our results demonstrate that Pinus
\end{abstract}


koraiensis pinecone is a readily available source of polyphenols, and the purified PPP could be a promising natural antitumor agent for applications in functional foods.

Keywords: pinecone of Pinus koraiensis; polyphenols purification; response surface methodology; antiproliferative activity; compound identification

\section{Introduction}

Cancer, with millions of new cancer patients diagnosed each year, remains a leading cause of mortality, second only to heart diseases [1,2]. A recent report reveals that tumor promotion is the only reversible event during cancer development [3]. Therefore, early intervention targets will inhibit cancerous cell proliferation. Moreover, epidemiology suggests dietary consumption of plant polyphenols is associated with a lower incidence of cancer [4]. Therefore, great efforts have been made to develop new antitumor agents from natural products $[5,6]$.

Pinaceae koraiensis is a kind of evergreen tree which belongs to the Pinus genus of the family Pinaceae. It is native to eastern Asia, and widely distributed in the northeast China [7]. Pine polyphenols, secondary plant metabolites, are important determinants of the nutritional qualities of $P$. koraiensis [8]. Pine polyphenols have been attracting the attention of many biologists due to their biological activities [9], such as anti-oxidant [10], anti-tumor [11], anti-microbial properties [12] and so on. In addition, $P$. koraiensis pinecone, a by-product in the processing of $P$. koraiensis seeds, has been studied partly due to its potential as a rich source of polyphenol compounds. However, researches on P. koraiensis pinecone have mainly focused on the separation of its biologically active compounds $[13,14]$ as crude polyphenols always contain chlorophyll, proteins, polysaccharides and other impurities, which limit their applications, therefore it is urgent to develop an efficient purification method to obtain a high purity form of PPP, so as to study its antitumor effects.

The purification methods for polyphenols mainly include liquid-liquid extraction [15], supercritical fluid extraction [16,17], membrane filtration [18-20], ion exchange [21] and resin adsorption [22-25]. Comparatively, the resin adsorption method is the most suitable one for the separation and purification of biologically active substances due to its low cost, high efficiency and simple procedure [26,27]. In particular, AB-8 macroporous resin has been widely used in purification of polyphenols because of its appropriate surface area and nuclear pore size $[23,28]$. However, there is only limited information on the purification of PPP by AB-8 macroporous resin.

Response surface methodology (RSM) is an effective statistical technique for optimizing complex processes. It can reduce the number of experimental trials needed to evaluate multiple parameters and their interactions [29]. Moreover, Box-Behnken design (BBD), as a type of response surface design, is also widely used in many researches [30-33]. Therefore, the first aim of the present study was to optimize the purification parameters of the polyphenol extracts of P. koraiensis pinecone (PPP) by RSM and investigate the antiproliferative properties of PPP on seven cancer cell lines. Next, HPLC-MS analyses were performed to identify the components of purified PPP. The overall aim of this study was to supply some new information on the purification and antiproliferative activity of PPP for the development and application of $P$. koraiensis pinecones. 


\section{Results and Discussion}

\subsection{Adsorption and Desorption on AB-8 Resin}

The adsorption and desorption performance relates to the capabilities of the macroporous resins and chemical features of the absorbed substance [34]. The adsorption and desorption ratios of PPP on AB-8 resin were verified and shown in Figure 1.

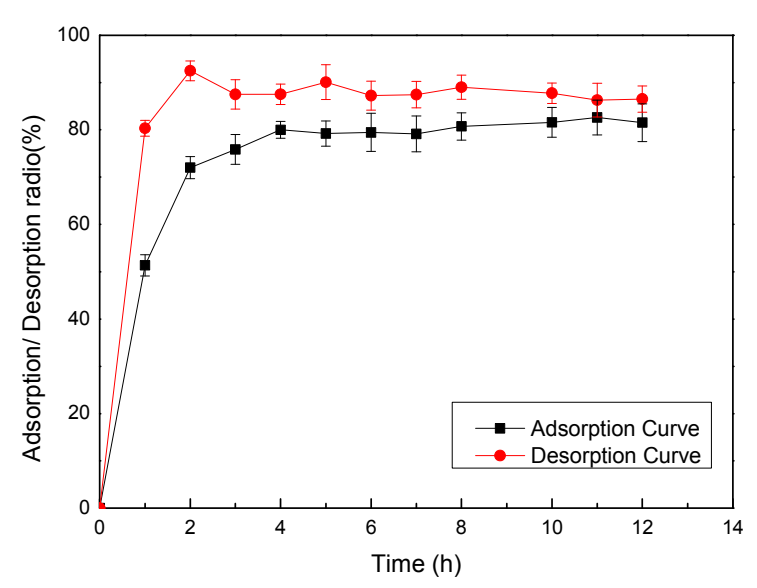

Figure 1. Static adsorption and desorption ratios of AB-8 resin at different time. Results were shown as means \pm standard deviation $(n=3)$.

Results indicated that $\mathrm{AB}-8$ resin possessed a high adsorption ratio and a higher desorption ratio, therefore, AB-8 resin was verified to be suitable for purification of PPP. More specifically, the adsorption ratio of PPP increased sharply during the first $2 \mathrm{~h}$, and then continued to increase much more slowly. After $4 \mathrm{~h}$, the adsorption level reached equilibrium which was likely due to the moderate polarity of AB-8 resin [35]. Therefore, the adsorption equilibrium was set at $4 \mathrm{~h}$ for later studies. Meanwhile, the desorption ratio also increased rapidly within $2 \mathrm{~h}$ to reach a maximum value and stay stable.

\subsection{Effect of Sample Phenolic Concentration on Purity of PPP}

The purification process was carried out using a range of sample phenolic concentrations from 1.0 to $3.5 \mathrm{mg} \mathrm{GAE} / \mathrm{mL}$ with a sample volume and an ethanol concentration of $30 \mathrm{~mL}$ and $60 \%(v / v)$, respectively. The effect of sample phenolic concentration on the purity of PPP is shown in Figure S1A (Supplementary Material). It was found that phenolic purity increased quickly to a maximum value of $25.08 \% \pm 0.81 \%$ as sample phenolic concentration increased from 1.0 to $1.5 \mathrm{mg} \mathrm{GAE} / \mathrm{mL}$, and then dropped rapidly until sample phenolic concentration exceeded $2.0 \mathrm{mg}$ GAE/mL before descending slowly. The results indicated that sample phenolic concentration of $1.5 \mathrm{mg}$ GAE/mL was optimal to obtain PPP of high purity.

\subsection{Effect of Sample Volume on Purity of PPP}

In this study, sample volumes were set at 10, 20, 30, 40, 50, and $60 \mathrm{~mL}$ while other parameters were set as follows: sample phenolic concentration of $1.5 \mathrm{mg}$ GAE $/ \mathrm{mL}$ and ethanol concentration of $60 \%$. As shown in Figure S1B (Supplementary Material), the purity significance was almost the same with a 
sample volume of 10 or $20 \mathrm{~mL}$, and the maximum purity of PPP was observed between 10 and $20 \mathrm{~mL}$. The highest purify was obtained with the optimized sample volumes, when the experimental error was taken into consideration. If the sample volume is too small, the error of the result would likely be bigger, so $20 \mathrm{~mL}$ was used in the experiments.

\subsection{Effect of Ethanol Concentration on Purity of PPP}

Purification processes were carried out at different ethanol concentrations of $20 \%, 30 \%, 40 \%, 50 \%$, $60 \%$ and $70 \%$, while sample phenolic concentration and sample volume were fixed at $1.5 \mathrm{mg} \mathrm{GAE} / \mathrm{mL}$ and $20 \mathrm{~mL}$, respectively. The effect of ethanol concentration on purity of PPP is shown in Figure S1C (Supplementary Material). The variance of phenolic purity increased first and then decreased with the increase of ethanol concentration, and peaked at $60 \%$. The results indicated that $60 \%$ ethanol was the most suitable for the purification of PPP, which may be related to the solvent polarity and the solubility of PPP.

\subsection{Optimization of Purification Parameters for PPP}

\subsubsection{Statistical Analysis and the Model Fitting}

A total of 15 runs were performed to optimize the three individual parameters in the current BBD as shown in Table 1.

Table 1. Box-Behnken experimental design with the independent variables $(n=3)$.

\begin{tabular}{|c|c|c|c|c|}
\hline Run & $X_{1}(\mathrm{mg} / \mathrm{mL})$ & $\mathrm{X}_{2}(\mathrm{~mL})$ & $X_{3}(\%)$ & Phenolic Purity (\%) \\
\hline 1 & 0 & 0 & 0 & 27.45 \\
\hline 2 & -1 & 0 & -1 & 15.46 \\
\hline 3 & 0 & -1 & 1 & 17.62 \\
\hline 4 & 1 & 0 & -1 & 19.21 \\
\hline 5 & -1 & -1 & 0 & 13.59 \\
\hline 6 & -1 & 0 & 1 & 17.11 \\
\hline 7 & 0 & -1 & -1 & 15.60 \\
\hline 8 & 1 & 0 & 1 & 24.90 \\
\hline 9 & 1 & 1 & 0 & 24.41 \\
\hline 10 & 0 & 0 & 0 & 27.14 \\
\hline 11 & 1 & -1 & 0 & 16.61 \\
\hline 12 & -1 & 1 & 0 & 16.35 \\
\hline 13 & 0 & 1 & 1 & 23.36 \\
\hline 14 & 0 & 1 & -1 & 18.16 \\
\hline 15 & 0 & 0 & 0 & 26.48 \\
\hline
\end{tabular}

$\mathrm{X}_{1}$ : sample phenolic concentration; $\mathrm{X}_{2}$ : sample volume; $\mathrm{X}_{3}$ : ethanol concentration.

The model for the response variable could be expressed by the following quadratic polynomial equation in the form of coded values:

$$
\begin{aligned}
& \mathrm{Y}=27.02+2.83 \mathrm{X}_{1}+2.36 \mathrm{X}_{2}+1.82 \mathrm{X}_{3}+1.26 \mathrm{X}_{1} \mathrm{X}_{2}+1.01 \mathrm{X}_{2} \mathrm{X}_{3}+0.80 \mathrm{X}_{1} \mathrm{X}_{3}-4.40 \mathrm{X}_{1}^{2}- \\
& 4.89 \mathrm{X}_{2}^{2}-3.45 \mathrm{X}_{3}^{2}
\end{aligned}
$$


where $\mathrm{Y}$ is the purity of PPP, and $\mathrm{X}_{1}, \mathrm{X}_{2}$ and $\mathrm{X}_{3}$ are the coded variables for sample phenolic concentration, sample volume and ethanol concentration, respectively.

Analysis of variance (ANOVA) for the fitted quadratic polynomial model of purification of PPP is shown in Table 2. The determination coefficient $\mathrm{R}^{2}$ was 0.9965 and suggested that $99.65 \%$ of the variations could be illustrated by the fitted model [36]. As shown in Table 2, the value of $\mathrm{R}^{2}$ adj was 0.9901 and was close to $\mathrm{R}^{2}$, which revealed that the model was highly significant. At the same time, the coefficient of variation $(\mathrm{CV}=2.38 \%)$ was a relatively small value which indicated a better reliability of the experimental values. Significance of model was also determined by lack-of-fit test. Table 2 shows $F$-value and $p$-value of the lack of fit were 0.91 and 0.5629 , respectively, which suggested that the lack of fit was not significant and the model was satisfactory. Moreover, the significance of each coefficient was also checked by the $p$-value. Table S2 (Supplementary Material) showed the cross product coefficients $\left(\mathrm{X}_{2} \mathrm{X}_{3}\right)$ were significant with small $p$-values $(p<0.05)$. The other term coefficients were also very significant $(p<0.01)$. These results suggested the model could be used to predict these responses.

Table 2. Analysis of variance for the fitted quadratic polynomial model of purification of PPP.

\begin{tabular}{cccccc}
\hline Source & $\mathbf{S S}^{\mathbf{a}}$ & $\mathbf{D F}^{\mathbf{b}}$ & $\mathbf{M S}^{\mathbf{c}}$ & $\boldsymbol{F}$-Value & Prob- $\boldsymbol{F}$ \\
\hline Modle & 325.17 & 9 & 36.13 & 156.06 & $<0.0001$ \\
Residual & 1.16 & 5 & 0.23 & & \\
Lack of fit & 0.67 & 3 & 0.22 & 0.91 & 0.5629 \\
Pure error & 0.49 & 2 & 0.25 & & \\
Cor.total & 326.33 & 14 & & & \\
\hline \multicolumn{7}{c}{} \\
\hline
\end{tabular}

${ }^{\mathrm{a}}$ Sums of squeares, ${ }^{\mathrm{b}}$ Degree freedom, ${ }^{\mathrm{c}}$ Mean square.

\subsubsection{Optimization of the Purification Conditions}

The 3D surface plots, which provide a method to visualize the relationship between responses and experimental levels of each variable [29] are shown in Figure 2. Figure 2A gives the ethanol concentration $\mathrm{X}_{3}\left(0\right.$ level) and shows the effects of sample phenolic concentration $\mathrm{X}_{1}$ and sample volume $\mathrm{X}_{2}$ on the phenolic purity. As the sample volume increased, the phenolic purity increased quickly at first until reaching a maximum and then decreased when the sample phenolic concentration was at a low level. Similarly, the increase of sample phenolic concentration caused an initial increase and a later decrease in the phenolic purity. This result indicated the phenolic purity was affected significantly by sample phenolic concentration and sample volume, which was also confirmed by the results in Table S2 (Supplementary Material).

Figure 2B shows a great increase in phenolic purity with an increase in sample phenolic concentration from 1.00 to $1.66 \mathrm{mg} \mathrm{GAE} / \mathrm{mL}$, and then a gradual decrease. The phenolic purity slowly increased then decreased with the increasing of ethanol concentration. These results indicated that $1.66 \mathrm{mg} \mathrm{GAE} / \mathrm{mL}$ and $63.14 \%$ were required to achieve maximum increase. 

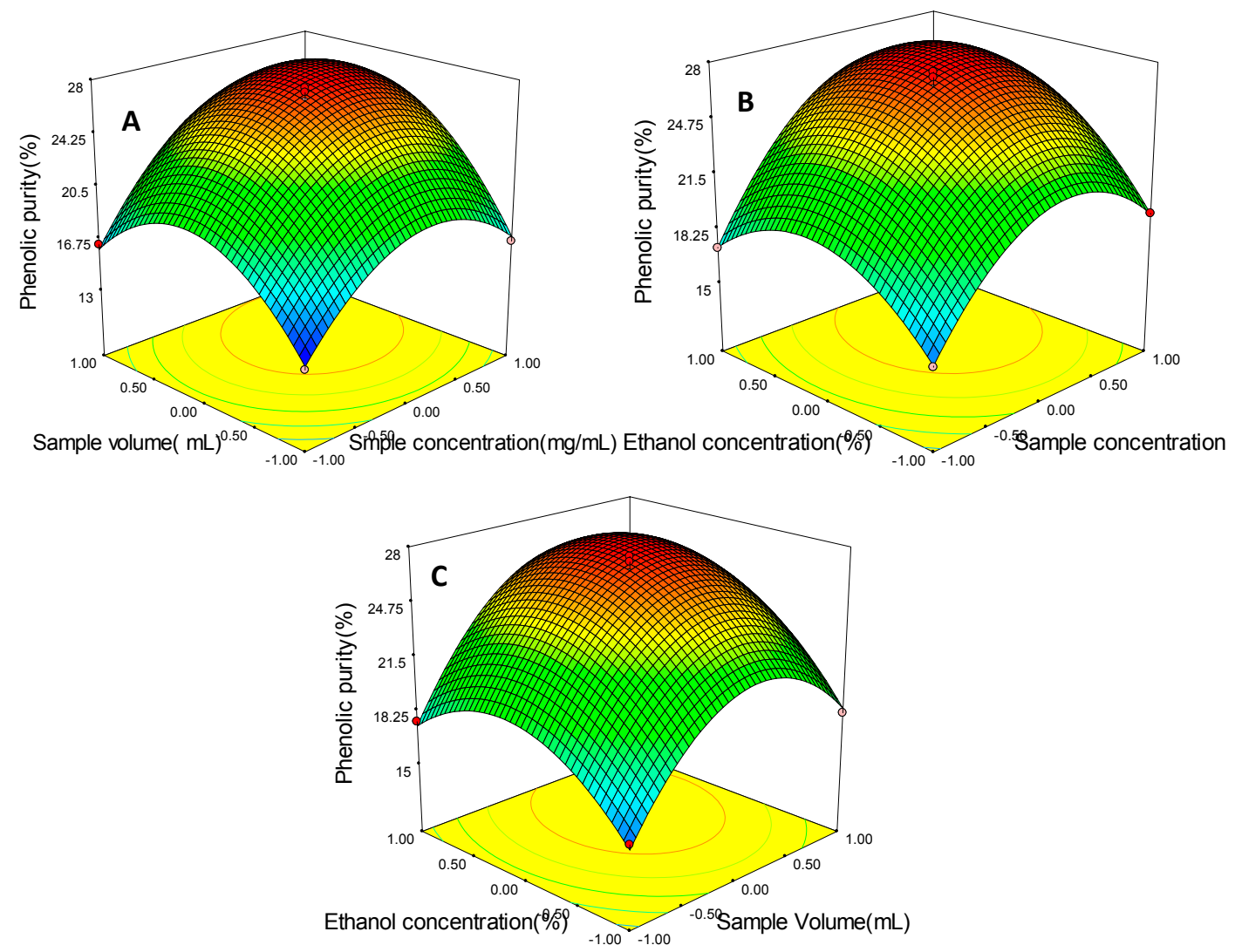

Figure 2. Response surface plots showing the effect of sample phenolic concentration $(\mathrm{mg} / \mathrm{mL})$, sample volume $(\mathrm{mL})$ and ethanol concentration $(\%)$ on the phenolic purity $(\%)$. (A) the effect of sample phenolic concentration (X1) and sample volume (X2); (B) the effect of sample phenolic concentration (X1) and ethanol concentration (X3); (C) the effect of sample volume (X2) and ethanol concentration (X3).

Figure $2 \mathrm{C}$ shows that the phenolic purity increased steadily with increasing ethanol concentration from $50 \%$ to $63.14 \%$, then decreased slowly. Similarly, phenolic purity increased rapidly with sample volume from $10 \mathrm{~mL}$ to $21.65 \mathrm{~mL}$ and decreased rapidly after $21.65 \mathrm{~mL}$, which indicated $21.65 \mathrm{~mL}$ was required to obtain maximum increase. According to Figure 2 above, it can be concluded that optimal purification conditions of PPP were sample phenolic concentration of $1.66 \mathrm{mg} \mathrm{GAE} / \mathrm{mL}$, sample volume of $21.65 \mathrm{~mL}$ and ethanol concentration of $63.14 \%$. Among the three purification parameters studied, sample phenolic concentration was the most significant factor affecting the phenolic purity according to the gradient of the slope in the $3 \mathrm{D}$ response surface plot.

\subsection{Verification of Predictive Model}

A high purity PPP was obtained with the optimized purification parameters, where the feasibility of the experiment was taken into consideration, so the suitability of the model equation for predicting the optimum response values was tested by using the optimal conditions with small modifications. Table 3 shows the maximum predicted and experimental phenolic purity. By using the predicted optimum conditions, the model predicted accordingly a maximum response of $28.17 \%$. In order to ensure the predicted result was not biased toward the actual value, experiment rechecking was performed by using these modified conditions: sample phenolic concentration of $1.70 \mathrm{mg}$ GAE/mL, sample volume of 
$22.00 \mathrm{~mL}$ and ethanol concentration of $63.00 \%$. The mean value of $27.93 \pm 0.14(\%)(n=3)$ obtained from real experiments, demonstrated the validation of the RSM model. The analysis results indicated that the model of Equation (4) was satisfactory and accurate.

Table 3 Predicted and experimental values of the responses at optimum and modified conditions. The actual experiment results were the means \pm standard deviation of three independent experiments $(n=3)$.

\begin{tabular}{ccccc}
\hline & $\begin{array}{c}\text { Sample Phenolic } \\
\text { Concentration (mg/mL) }\end{array}$ & $\begin{array}{c}\text { Sample } \\
\text { Volume (mL) }\end{array}$ & $\begin{array}{c}\text { Ethanol } \\
\text { Concentration (\%) }\end{array}$ & $\begin{array}{c}\text { Phenolic } \\
\text { Purity (\%) }\end{array}$ \\
\hline $\begin{array}{c}\text { Optimum Conditions } \\
\text { (predicted) }\end{array}$ & 1.66 & 21.65 & 63.14 & 28.17 \\
$\begin{array}{c}\text { Modified Conditions } \\
\text { (actual) }\end{array}$ & 1.70 & 22.000 & 63.00 & $27.93 \pm 0.14$ \\
\hline
\end{tabular}

\subsection{Antiproliferative Activity of PPP}

Next, the antiproliferative activities of PPP were evaluated against the A375, A549, SH-SY5Y, LOVO, MCF-7, HeLa and HT29 cell lines by MTT assays. There was a considerable difference in the sensitivity of the seven cancer cell lines towards PPP, as presented in Figure 3A. Overall, PPP roughly inhibited the proliferation of the seven kinds of cells in dose dependent manner. It showed strong anti-proliferative effects on the three cancer cell lines of LOVO, HT29 and HeLa with antiproliferatition rates of $80 \%, 70 \%$ and $65 \%$, respectively, when the PPP concentration was $1.0 \mathrm{mg} / \mathrm{mL}$. For the rest of the cell lines (A375, MCF-7, A549 and SY5Y), PPP showed relatively poor inhibition effects with no higher than $40 \%$ anti-proliferation rates. Phenolic-rich extracts have been widely investigated for their potential antiproliferative properties against a variety of cancer cells, and some of them also have shown promising results [37-39].
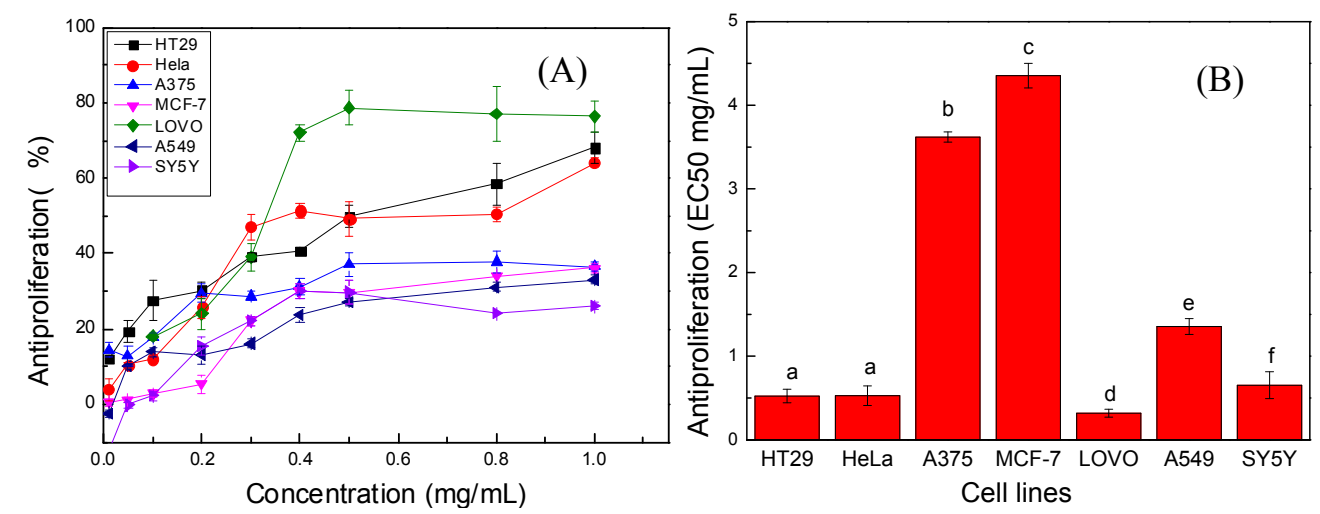

Figure 3. Antiproliferative effects of PPP on seven cancer cells. (A) Inhibition of seven cells proliferation with treatment of different concentrations of PPP; (B) The EC50 values for the inhibition of seven cells growth by PPP. Results were represented as means \pm standard deviation of three parallel measurements followed by the different letters, which indicated significantly different $(p<0.05),(n=3)$. 
Antiproliferative activity was expressed as the $50 \%$ effective concentration $\left(\mathrm{EC}_{50}\right)$, where a low $\mathrm{EC}_{50}$ value means a high antiproliferative value. Based on the $\mathrm{EC}_{50}$ values in Figure 3B, the antiproliferation effects of the PPP on the seven cell lines were in the following decreasing order: MCF-7 > A375 > A549 $>$ SH-SY5Y > HeLa $>$ HT29 > LOVO. The antiproliferative ratio of PPP against LOVO cells was the highest (Figure 3A), and the EC50 value of the LOVO cell line $(0.317 \pm 0.0476 \mathrm{mg} / \mathrm{mL})$ was also the lowest accordingly in all the cancer cell lines $(p<0.05)$ (Figure 3B).

In our study, PPP showed different antiproliferative effects on the seven target cancer cell lines, which indicated that different cancer cells had different sensibility against the same test sample. This is in accordance with report of Fan et al that human liver cancer HepG2 cells were more sensitive to fruit extract treatment than colon cancer HT-29 cells [40]. Furthermore, the PPP concentrations employed in the assay have been normalized, suggesting that the different antiproliferative responses on seven cells were associated with the polyphenol compositions of PPP, rather than the polyphenol contents. Thus LOVO cells were inferred to be more vulnerable to the major polyphenols from Pinus koraiensis in our study.

\subsection{UPLC-Q-TOF-MS Analysis of Purified PPP}

Tentative characterization of purified PPP was generated based on elemental composition data determined by UPLC-MS. Figure 4A shows the total ion chromatogram (TIC) of purified PPP.

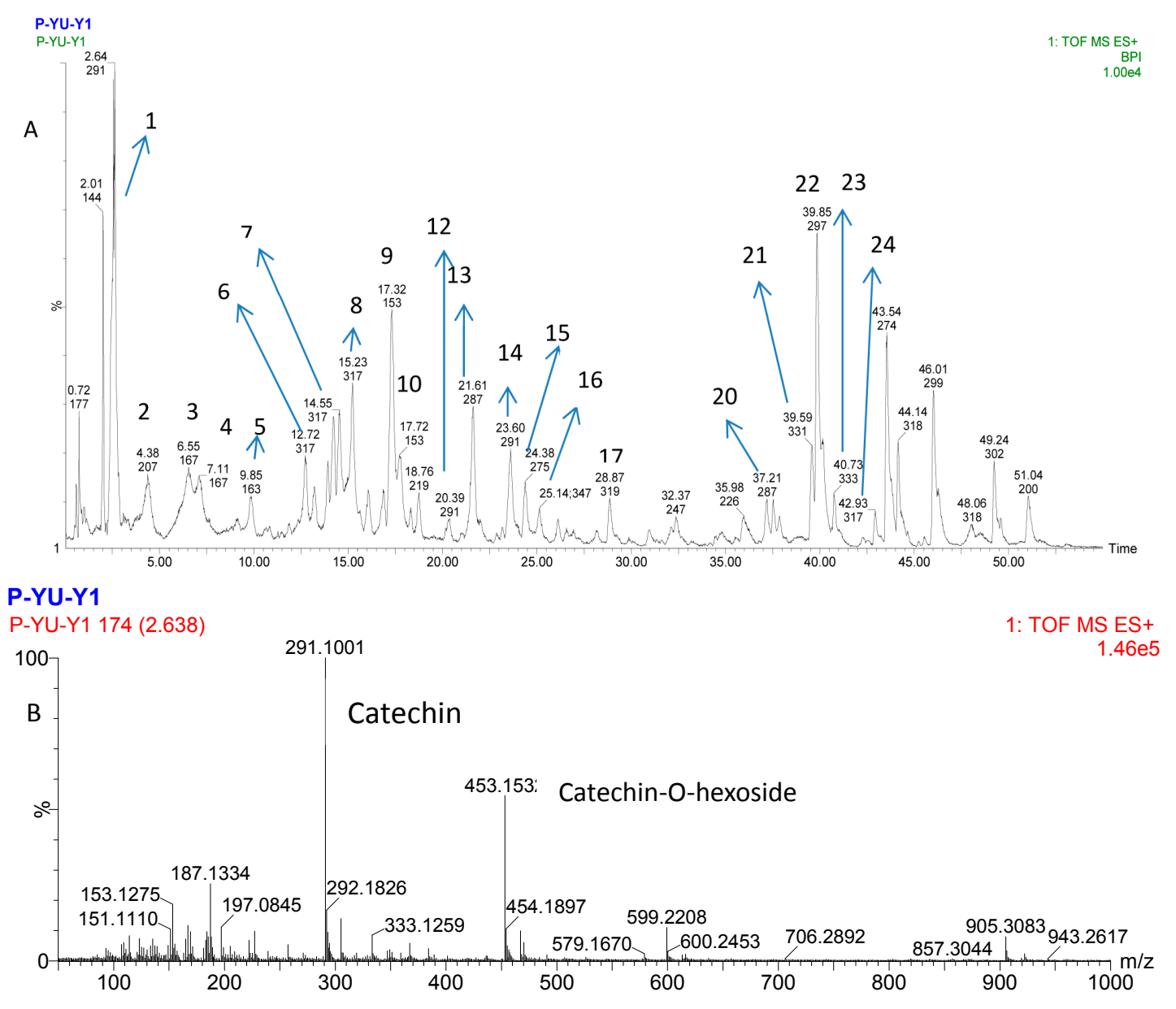

Figure 4. Cont. 


\section{P-YU-Y1}

P-YU-Y1 1009 (15.232)

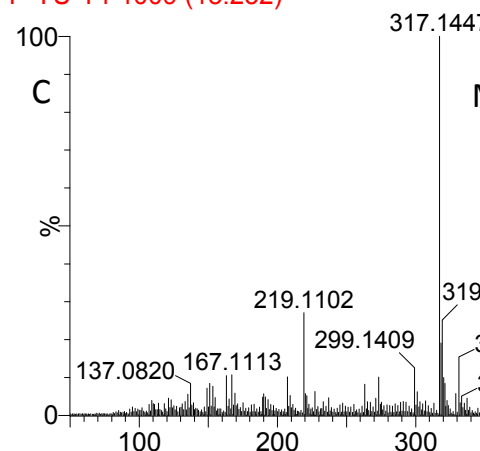

17.1447

1: TOF MS ES+

$5.98 \mathrm{e} 4$

Methyl quercetin

\section{P-YU-Y1}

P-YU-Y1 1148 (17.315)

$100 \quad 153.1292$

D. $\quad$ O-Vanillin

300

$2057 \quad 496.2407540 .2764$ \begin{tabular}{llll}
655.2802685 .3191 & 869.3369 & 974.4429 \\
\hline
\end{tabular}

\section{0}

$500 \quad 600$

800

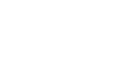

1: TOF MS ES+

$9.38 \mathrm{e} 4$

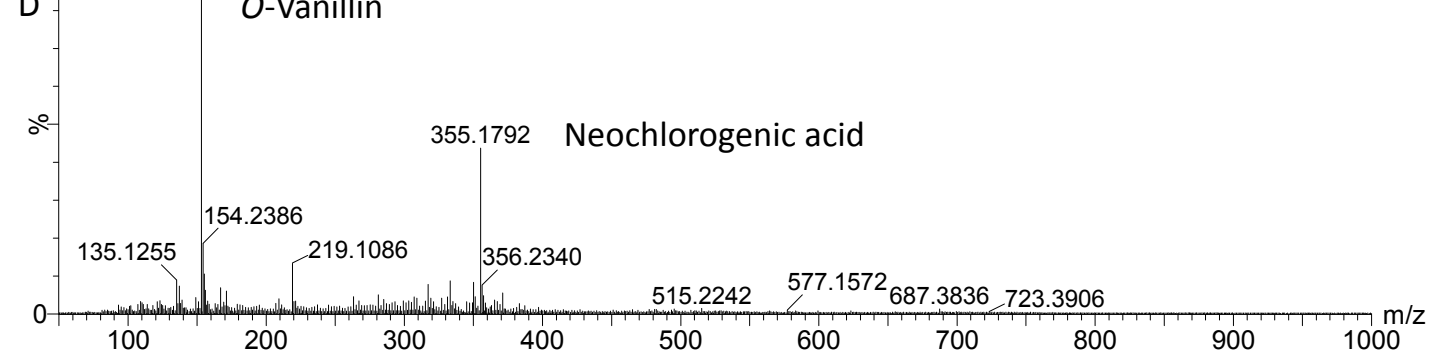

P-YU-Y1

P-YU-Y1 1435 (21.642)

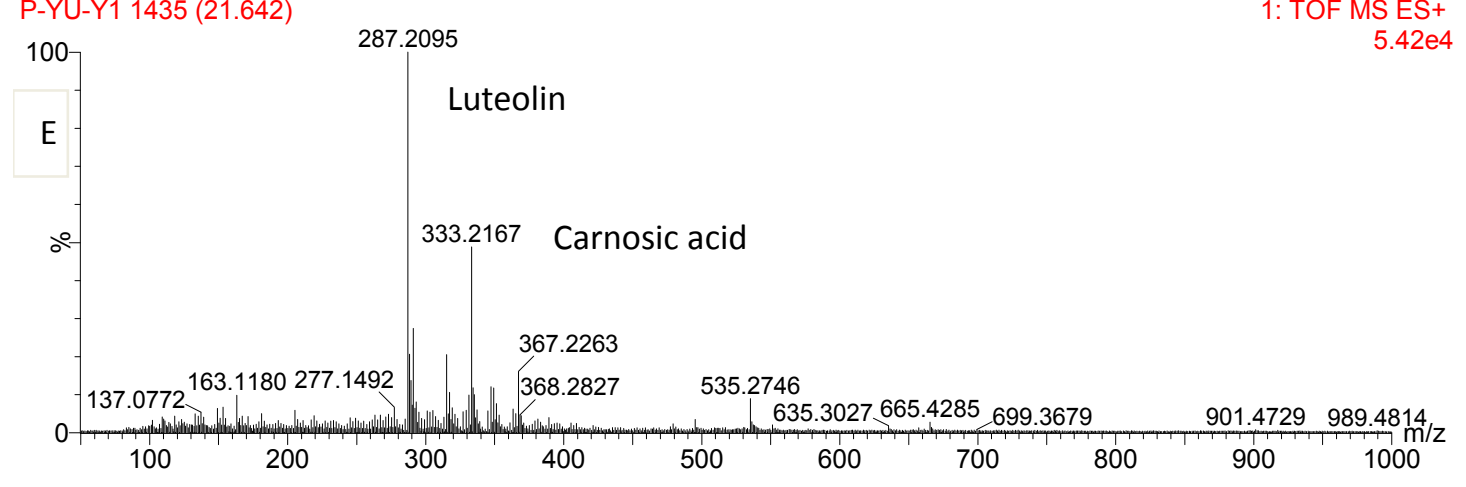

P-YU-Y1

P-YU-Y1 2643 (39.846)

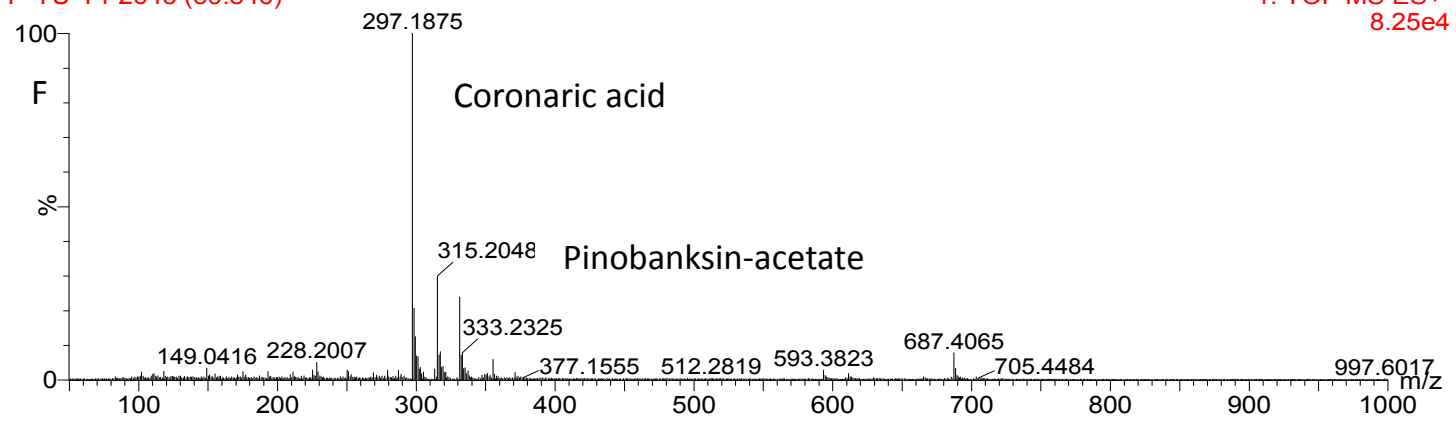

Figure 4. UPLC-Q-TOF-MS total ion chromatogram (TIC) of purified PPP and the ion chromatograms of representative peaks. (A) Total ion chromatographic profiling of purified PPP; (B) MS/MS spectrum of peak 1; (C) MS/MS spectrum of peak 8; (D) MS/MS spectrum of peak 9; (E) MS/MS spectrum of peak 13; (F) MS/MS spectrum of peak 22. Mass spectral data positive mode of phenolics. 
The phenolic compounds were tentatively identified on the basis of comparisons of their retention time and mass spectra with literature data [41-51]. The TIC obtained revealed the presence of twenty-four peaks in the purified PPP and listed in Table 4. Five representative peaks identified as catechin, methyl quercetin, $o$-vanillin, luteolin and coronaric acid, respectively, are in Figure 4B-F.

As reported in the literature [41-43], the UPLC catechin elutes prior to epicatechin, thus, peak 1 and 12 (14) were identified as catechin (Figure 4B) and epicatechin, respectively. Peaks 6, 7, 8 and 24 with $[\mathrm{M}+\mathrm{H}]^{+}$at $m / z 317$ were identified as 3-hydroxy-4-O- $\beta$-glucosylbenzoic acid, isorhamnetin, methyl quercetin (Figure 4C) and tamarixetin according to previous reports and the obtained mass spectra [42-45]. Both peaks 9 and 10 yielded $m / z 153[\mathrm{M}+\mathrm{H}]^{+}$peaks, and $o$-vanillin (Figure 4D) and $p$-vanillin were identified by examining the known literature data [46]. Peaks $13(\mathrm{~m} / z$ 287) and 22 ( $m / z$ 297) were characterized as luteolin and coronaric acid, respectively (Figure 4E-F) [45,47,48]. In addition, by comparing the mass spectra with literatures, peaks 16 and 17 were also identified as isorhamnetin, rosmanol isomer and myricetin [46,49]. Peaks 20, 21 and 23 showed $[\mathrm{M}+\mathrm{H}]^{+}$peaks at $\mathrm{m} / \mathrm{z}$ 287, 331 and 333, which was identified as kaempferol, carnosol isomer and monogalloyl glucose, respectively $[44,49]$. Identifications of other peaks were strongly correlated with the studied references values $[41,42,45,47,50,51]$.

Table 4. Identification of purified PPP by UPLC-MS. Mass spectral data positive mode.

\begin{tabular}{cccccc}
\hline Peak & $\mathbf{t}_{\mathbf{R}}(\mathbf{m i n})$ & $\mathbf{M S}(\boldsymbol{m} / \boldsymbol{z})$ & $\mathbf{M W}$ & Molecular Formula & Identification \\
\hline 1 & 2.64 & 291 & 290 & $\mathrm{C}_{15} \mathrm{H}_{14} \mathrm{O}_{6}$ & Catechin \\
2 & 4.38 & 207 & 206 & $\mathrm{C}_{11} \mathrm{H}_{10} \mathrm{O}_{4}$ & Scopoletin $+\mathrm{CH} 2$ \\
3 & 6.55 & 167 & 166 & $\mathrm{C}_{8} \mathrm{H}_{7} \mathrm{O}_{4}$ & Vanillic acid-H \\
4 & 7.11 & 167 & 166 & $\mathrm{C}_{8} \mathrm{H}_{7} \mathrm{O}_{4}$ & Vanillic acid-H \\
6 & 12.72 & 317 & 316 & $\mathrm{C}_{16} \mathrm{H}_{12} \mathrm{O}_{7}$ & 3-Hydroxy-4-O- $\beta$-glucosylbenzoic acid \\
7 & 14.55 & 317 & 316 & $\mathrm{C}_{16} \mathrm{H}_{12} \mathrm{O}_{7}$ & Isorhamnetin \\
8 & 15.23 & 317 & 316 & $\mathrm{C}_{16} \mathrm{H}_{12} \mathrm{O}_{7}$ & Methyl quercetin \\
9 & 17.32 & 153 & 152 & $\mathrm{C}_{8} \mathrm{H}_{8} \mathrm{O}_{3}$ & $o$-Vanillin \\
10 & 17.72 & 153 & 152 & $\mathrm{C}_{8} \mathrm{H}_{8} \mathrm{O}_{3}$ & $p$-Vanillin \\
12 & 20.39 & 291 & 290 & $\mathrm{C}_{15} \mathrm{H}_{14} \mathrm{O}_{6}$ & Epicatechin \\
13 & 21.61 & 287 & 286 & $\mathrm{C}_{15} \mathrm{H}_{10} \mathrm{O}_{6}$ & Luteolin \\
14 & 23.60 & 291 & 290 & $\mathrm{C}_{15} \mathrm{H}_{14} \mathrm{O}_{6}$ & Epicatechin \\
15 & 24.38 & 275 & 274 & $\mathrm{C}_{15} \mathrm{H}_{14} \mathrm{O}_{5}$ & Phloretin \\
16 & 25.14 & 347 & 346 & $\mathrm{C}_{20} \mathrm{H}_{26} \mathrm{O}_{5}$ & Rosmanol isomer \\
17 & 28.87 & 319 & 318 & $\mathrm{C}_{15} \mathrm{H}_{10} \mathrm{O}_{8}$ & Myricetin \\
20 & 37.21 & 287 & 286 & $\mathrm{C}_{15} \mathrm{H}_{10} \mathrm{O}_{6}$ & Kaempferol \\
21 & 39.59 & 331 & 330 & $\mathrm{C}_{20} \mathrm{H}_{26} \mathrm{O}_{4}$ & Carnosol isomer \\
22 & 39.85 & 297 & 296 & $\mathrm{C}_{18} \mathrm{H}_{32} \mathrm{O}_{3}$ & Coronaric acid \\
23 & 40.73 & 333 & 332 & $\mathrm{C}_{16} \mathrm{H}_{12} \mathrm{O}_{6}$ & Monogalloyl glucose \\
24 & 42.93 & 317 & 316 & $\mathrm{C}_{16} \mathrm{H}_{12} \mathrm{O}_{7}$ & Tamarixetin \\
\hline
\end{tabular}

These identified polyphenol compositions may play a key role in the biological activities of PPP, especially, the catechin and epicatechin components (peak 1 and peak 12) may be closely related with the antitumor activity of PPP. The phenolic compositions of Annurca apple peel also showed that higher amounts of procyanidins (catechin and epicatechin) possessed the most effective antitumor function [52]. Some authors also have proved the antitumor activities of polyphenols were associated 
with their composition. Corsi et al. proved in their studies that gallic acid showed a higher inhibition capacity for HeLa cells than cinnamic acid [53]. The aqueous extract of carob pod was composed mainly by gallic acid and gallotannins, and exerted a good antiproliferative effect on T1 cell lines [54]. Anthocyanin-rich black currant extract and pitaya peel polyphenols significantly inhibited the growth of HepG2 cells and B16F10 melanoma cancer cells, respectively $[55,56]$.

Moreover, these differences in functional activities also may be attributed to their different active components. Serra and others found that among phenolic compounds catechin and procyanidin B1 were the major contributors to the antioxidant activity of apples, whereas procyanidins (B1 and B2), phloridzin and epicatechin played an important role against human cancer cell proliferation [57].

\section{Experimental Section}

\subsection{Samples and Chemicals}

The dried pinecones of $P$. koraiensis were provided by the Forestry Bureau (Yichun, China). AB-8 macroporous resin was obtained from Soledad Technology Ltd. (Beijing, China) and was pretreated according to Sun et al. [29]. Roswell Park Memorial Institute 1640 (RPMI-1640) medium and fetal bovine serum (FBS) were provided from Hyclone Chemical Co. (Hyclone, Logan, UT, USA). Other chemicals were commercially available from local suppliers.

\subsection{Extraction Procedure of PPP}

The dried pinecones of $P$. koraiensis were smashed and passed through 30 mesh sieves. The pinecone powders were added to $60 \%$ ethanol (1:20), and subjected to ultrasonic treatment at $50{ }^{\circ} \mathrm{C}$ and $400 \mathrm{~W}$ for $1 \mathrm{~h}$, then the extraction above was repeated twice. The extracts were combined and separated by filtration on a Buchner funnel, then centrifuged at $4000 \mathrm{rpm}$ for $10 \mathrm{~min}$. The supernatant was concentrated by rotary evaporation to afford the crude PPP.

\subsection{Determination of Total Phenolic Content (TPC)}

TPC was determined by the Folin-Ciocalteu method using gallic acid as a standard. Briefly, $1.0 \mathrm{~mL}$ of sample solution was mixed with $1.0 \mathrm{~mL}$ of Folin-Ciocalteu reagent and reacted for $5 \mathrm{~min}$ at $25^{\circ} \mathrm{C}$. Then, $1.0 \mathrm{~mL}$ of saturated $\mathrm{Na}_{2} \mathrm{CO}_{3}(10 \% \mathrm{w} / \mathrm{v})$ and $1.0 \mathrm{~mL}$ of distilled water were added. The reaction mixture was kept at $25^{\circ} \mathrm{C}$ for $2 \mathrm{~h}$ in the dark. Absorbance was measured at $765 \mathrm{~nm}$. TPC was expressed as $\mathrm{mg}$ gallic acid equivalent per $\mathrm{mL}$ of sample solution $(\mathrm{mg} \mathrm{GAE} / \mathrm{mL})$.

\subsection{Static Adsorption and Desorption of AB-8 Resin Test}

The pretreated AB-8 resins $(5.0 \mathrm{~g})$ and $50 \mathrm{~mL}$ of PPP $(1.5 \mathrm{mg}$ GAE$/ \mathrm{mL})$ were added to a $250 \mathrm{~mL}$ air-tight flask. Then, the flask was shaken at $100 \mathrm{rpm}$ for $12 \mathrm{~h}$ to reach the equilibrium. Next, the residual PPP solution was removed first. Then, the AB- 8 resins were washed with distilled water and desorbed by $50 \mathrm{~mL} 60 \%(v / v)$ ethanol solution in a flask, which was shaken at $100 \mathrm{rpm}$ for $12 \mathrm{~h}$. The TPC of the solution was determined at $1 \mathrm{~h}$ intervals. The adsorption and desorption ratios were calculated using Equations (1) and (2), respectively: 


$$
\begin{gathered}
E=100\left(C_{0}-C_{t}\right) / C_{0} \\
D=100 C_{d} V_{d} /\left[V_{0}\left(C_{0}-C_{e}\right)\right]
\end{gathered}
$$

where $E$ is the adsorption ratio (\%); $C_{0}$ and $C_{t}$ are the TPC of the sample solution at beginning and at time $t$, respectively (mg GAE/mL); $D$ is the desorption ratio (\%), $C_{d}$ is the TPC of the desorption solution $(\mathrm{mg} \mathrm{GAE} / \mathrm{mL}) ; V_{d}$ is the desorption solution volume $(\mathrm{mL}) ; V_{0}$ is the initial volume of PPP $(\mathrm{mL}) ; C_{e}$ is the equilibrium TCP in the sample solution.

\subsection{Determination of Total Phenolic Purity (TPP)}

Briefly, the crude PPP was dynamically adsorbed on a glass column packed with AB-8 resin. Based on the result of the static AB-8 resin adsorption experiments, the equilibrium time was chosen as $4 \mathrm{~h}$. Distilled water was first used to remove sugars, acids and other water-soluble compounds. Then, the crude PPP was eluted with ethanol at a constant flow velocity of $1.5 \mathrm{~mL} / \mathrm{min}$, and two bed volumes (BV) of phenolic eluent was collected and concentrated in a rotary evaporator to afford the purified PPP. TPP (\%) was calculated as per Equation (3):

$$
\text { Phenolic purity }(\%)=\left(\frac{\text { Purified polyphenols weight }}{\text { total solids weight }}\right) \times 100 \%
$$

\subsection{Experimental Design}

The single-test method was first used to determine the preliminary ranges of the purification variables. Then, BBD was employed to optimize three independent variables (sample phenolic concentration $\mathrm{X}_{1}$, sample volume $\mathrm{X}_{2}$, ethanol concentration $\mathrm{X}_{3}$ ) for the purification of PPP in this optimization study. Table S1 (Supplementary Material) shows the three levels of these independent variables. Phenolic purity (Y) was taken as a response for the design experiment shown in Table 1. The behavior of the system was explained by Equation (4):

$$
Y=A_{0}+\sum_{i=1}^{3} A_{i} X_{i}+\sum_{i=1}^{3} A_{i i} X_{i}^{2}+\sum_{i=1}^{2} \sum_{j=i+1}^{3} A_{i j} X_{i} X_{j}
$$

where $Y$ is the dependent variable, $A_{0}$ is a constant, and $\mathrm{A}_{\mathrm{i}}, \mathrm{A}_{i i}$, and $A_{i j}$ are coefficients estimated by the model. $X_{i}$ and $X_{j}$ are levels of the independent variables while $A_{0}, A_{i}, A_{i i}$, and $A_{i j}$ are the regression coefficients for the intercept, linearity, square, and interaction, respectively.

\subsection{Cell Culture}

The A375, A549, SH-SY5Y cell lines were provided by Harbin Medical University. The MCF-7 cell line was obtained from School of Life Science of Harbin Institute of Technology. HeLa and T29 cell lines were preserved by the School of Food Science and Engineering of Harbin Institute of Technology. The seven cell lines were grown in RPMI-1640 containing 10\% heat-inactivated FBS and maintained in a $5 \% \mathrm{CO}_{2} / 37^{\circ} \mathrm{C}$ incubator $[58,59]$. 


\subsection{Measurement of Antiproliferation of PPP on Cancer Cells}

The antiproliferative activities of samples were measured by the MTT assay. The cancer cell lines $\left(1 \times 10^{5}\right.$ cells $\left./ \mathrm{mL}\right)$ were transferred to 96 -well flat-bottom plates containing RPMI-1640 medium. The cells were allowed to settle overnight. After incubation, the medium was changed to $100 \mu \mathrm{L}$ of growth medium added with various concentrations of samples in each well and incubated for another 48 at $37{ }^{\circ} \mathrm{C}$ in $5 \% \mathrm{CO}_{2}$. Then, $10 \mu \mathrm{L}$ of MTT solution $(0.5 \mathrm{mg} / \mathrm{mL})$ was added to each well. After $4 \mathrm{~h}$ of incubation, the untrasformed MTT was carefully removed and the precipitated formazan was dissolved in the $150 \mu \mathrm{L}$ of DMSO per well, then shaken for $15 \mathrm{~min}$, Cell antiproliferation (\%) was determined at $490 \mathrm{~nm}$ and was calculated by Equation (5) [40,60]. All samples were conducted in triplicate:

Antiproliferative rate $(\%)=100 \times($ absorbance of control - absorbance of treated cells $) /$ absorbance of control

\subsection{Identification of Purified PPP by UPLC-Q-TOF-MS}

The purified PPP was analyzed using a UPLC (ACQUITYтм, Waters Technologies, Milford, MA, USA) equipped with a HSS T3 column $(2.1 \times 100 \mathrm{~mm}, 1.8 \mu \mathrm{m}$, waters). Eluent (A) and eluent (B) were methanol and acidified water $(0.1 \%$ formic acid, $v / v)$, respectively. The elution program was as follows: 0-30 $\min (5 \%-25 \% \mathrm{~A}), 30-40 \min (25 \%-35 \% \mathrm{~A}), 40-50 \min (35 \%-50 \% \mathrm{~A}), 50-51 \mathrm{~min}(50 \%-5 \% \mathrm{~A})$, 51-60 $\mathrm{min}(5 \% \mathrm{~A})$. And the operating conditions were: flow rate, $0.16 \mathrm{~mL} / \mathrm{min}$; column temperature, $30{ }^{\circ} \mathrm{C}$; injection volume, $10 \mu \mathrm{L}$. UV-Vis absorption spectra were monitored at $280 \mathrm{~nm}$. The UPLC system was coupled to Xevo QTof MS (Waters Technologies) equipped with an ESI source. The analysis parameters were set using positive ion mode with spectra acquired over a mass rang from $\mathrm{m} / \mathrm{z} 100$ to 1200. The ESI-MS parameters were set to voltage, $+4.5 \mathrm{kv}$; dring gas temperature, $325{ }^{\circ} \mathrm{C}$; dring gas flow, $10 \mathrm{~L} / \mathrm{min}$.

\subsection{Statistical Analysis}

Analysis of the experimental design and calculation of predicted data were carried out using Design Expert (version 7.0, Stat-Ease, Inc., Minneapolis, MN, USA) to estimate the responses to the independent variables. All analytical measurements were run at least in triplicate unless specified otherwise. Values were averaged and given with the standard deviation $( \pm \mathrm{SD})$.

\section{Conclusions}

In this paper, AB-8 resin was first verified to possess good adsorption and desorption ratios for PPP purification. Then, RSM with BBD was used to optimize the experimental variables, and the optimal conditions determined were as follows: sample phenolic concentration of $1.70 \mathrm{mg} \mathrm{GAE} / \mathrm{mL}$, sample volume of $22.00 \mathrm{~mL}$ and ethanol concentration of $63.00 \%$. Under these optimal conditions, a maximum phenolic purity of $27.93 \% \pm 0.14 \%$ could be achieved. In addition, the in vitro antiproliferative activities of PPP on seven cancer cell lines were evaluated. The results showed that PPP had the strongest inhibition on the proliferation of LOVO in a dose-dependent manner $(p<0.05)$. This result also indicated that the same components of PPP possessed selective antiproliferative effects against different target cell lines. Finally, twenty-four peaks were tentatively identified by UPLC-MS, of which five 
representative peaks were identified as catechin, methyl quercetin, $o$-vanillin, luteolin and coronaric acid in the purified PPP. The results indicated that Pinus koraiensis pinecone is a valuable source of polyphenols. Furthermore, this study also provided some useful information for the development of PPP as an antitumor drug.

\section{Supplementary Materials}

Supplementary materials can be accessed at: http://www.mdpi.com/1420-3049/20/06/10450/s1.

\section{Acknowledgment}

The authors gratefully acknowledge the financial support by National Natural Science Foundation of China (no. 31170510). We thank Professor Wei Song for providing language help and proof reading the article.

\section{Author Contributions}

Zhenyu Wang designed and supervised the research project. Juanjuan Yi finished all of the experiments and wrote the paper. Haina Bai, Xiaojin Yu, Jing Jing and Lili Zuo assisted in research and conducted the bioinformatic analysis.

\section{Conflicts of Interest}

The authors declare no conflict of interest.

\section{Nonstandard Abbreviations}

Pinus koraiensis: P. koraiensis; polyphenols of P. koraiensis pinecone: PPP; Response surface methodology: RSM; Box-Behnken design: BBD; Gallic acid equivalent: GAE; Bed volume: BV; High performance liquid chromatography-tandem mass spectrometry: HPLC-MS.

\section{References}

1. Khonkarn, R.; Okonogi, S.; Ampasavate, C.; Anuchapreeda, S. Investigation of fruit peel extracts as sources for compounds with antioxidant and antiproliferative activities against human cell lines. Food Chem. Toxicol. 2010, 48, 2122-2129.

2. Hu, T.; He, X.W.; Jiang, J.G.; Xu, X.L. Hydroxytyrosol and Its Potential Therapeutic Effects. J. Agric. Food Chem. 2014, 62, 1449-1455.

3. Happy, M.; Dejoie, J.; Zajac, C.K.; Cortez, B.; Chakraborty, K.; Aderemi, J.; Sauane, M. Sigma 1 Receptor antagonist potentiates the anti-cancer effect of $\mathrm{p} 53$ by regulating ER stress, ROS production, Bax levels, and caspase-3 activation. Biochem. Biophys. Res. Commun. 2015, 456, 683-688.

4. Liu, J.R.; Dong, H.W.; Chen, B.Q.; Zhao, P.; Liu, R.H. Fresh apples suppress mammary carcinogenesis and proliferative activity and induce apoptosis in mammary tumors of the Sprague-Dawley rat. J. Agric. Food Chem. 2009, 57, 297-304. 
5. Ouyang, L.; Luo, Y.; Tian, M.; Zhang, S.Y.; Lu, R.; Wang, J.H.; Kasimu, R.; Li, X. Plant natural products: From traditional compounds to new emerging drugs in cancer therapy. Cell Prolif. 2014, 47, 506-515.

6. Lee, S.K.; Jung, H.S.; Eo, W.K.; Lee, S.Y.; Kim, S.H.; Shim, B.S. Rhus verniciflua Stokes extract as a potential option for treatment of metastatic renal cell carcinoma: Report of two cases. Ann. Oncol. 2010, 21, 1383-1385.

7. Yang, X.; Zhang, H.; Zhang, Y.; Ma, Y.; Wang, J. Two new diterpenoid acids from Pinus koraiensis. Fitoterapia 2008, 79, 179-181.

8. Ignat, I.; Volf, I.; Popa, V.I. A critical review of methods for characterisation of polyphenolic compounds in fruits and vegetables. Food Chem. 2011, 126, 1821-1835.

9. Kim, N.Y.; Jang, M.K.; Lee, D.G.; Yu, K.H.; Jang, H.J.; Kim, M.; Kim, S.G.; Yoo, B.H.; Lee, S.H. Comparison of methods for proanthocyanidin extraction from pine (Pinus densiflora) needles and biological activities of the extracts. Nutr. Res. Pract. 2010, 4, 16-22.

10. Chen, X.Q.; Zhang, Y.; Wang, Z.Y.; Zu, Y.G. In vivo antioxidant activity of Pinus koraiensis nut oil obtained by optimised supercritical carbon dioxide extraction. Nat. Prod. Res. 2011, 25, 1807-1816.

11. Li, K.; Li, Q.; Li, J.; Zhang, T.; Han, Z.; Gao, D.; Zheng, F. Antitumor Activity of the Procyanidins from Pinus koraiensis Bark on Mice Bearing U14 Cervical Cancer. Yakugaku Zasshi 2007, 127, $1145-1151$.

12. Lee, J.H.; Yang, H.Y.; Lee, H.S.; Hong, S.K. Chemical composition and antimicrobial activity of essential oil from cones of Pinus koraiensis. J. Microbiol. Biotechnol. 2008, 18, 497-502.

13. Su, X.; Wang, J.; Yang, X.; Cao, W. Analysis of volatile oil constituents in pinecone of Pinus koraiensis by gas chromatography-mass spectrometry. Chin. J. Anal. Chem. 2006, 34, S217-S219.

14. Zou, P.; Yang, X.; Huang, W.W.; Zhao, H.T.; Wang. J.; Xu, R.B.; Hu, X.L.; Shen, S.Y.; Qin, D. Characterization and Bioactivity of Polysaccharides Obtained from Pine Cones of Pinus koraiensis by Graded Ethanol Precipitation. Molecules 2013, 18, 9933-9948.

15. Nave, F.; Cabrita, M.J.; Costa, C.T. Use of solid-supported liquid-liquid extraction in the analysis of polyphenols in wine. J. Chromatogr. A 2007, 1169, 23-30.

16. Russo, C. A new membrane process for the selective fractionation and total recovery of polyphenols, water and organic substances from vegetation waters (VW). J. Membr. Sci. 2007, 2288, 239-246.

17. Farías-Campomanes, A.M.; Rostagno, M.A.; Meireles, M.A. Production of polyphenol extracts from grape bagasse using supercritical fluids: Yield, extract composition and economic evaluation. J. Supercrit. Fluid. 2013, 77, 70-78.

18. Arriagada-Carrazana, J.P.; Sáez-Navarrete, C.; Bordeu, E. Membrane filtration effects on aromatic and phenolic quality of Cabernet Sauvignon wines. J. Food Eng. 2005, 68, 363-368.

19. Conidi, C.; Cassano, A.; Drioli, E. A membrane-based study for the recovery of polyphenols from bergamot juice. J. Membr. Sci. 2011, 375, 182-190.

20. Garcia-Castello, E.; Cassano, A.; Criscuoli, A.; Conidi, C.; Drioli, E. Recovery and concentration of polyphenols from olive mill wastewaters by integrated membrane system. Water Res. 2010, 44, 3883-3892.

21. Kammerer, J.; Kammerer, D.R.; Carle, R. Impact of saccharides and amino acids on the interaction of apple polyphenols with ion exchange and adsorbent resins. J. Food Eng. 2010, 98, 230-239. 
22. Li, P.; Wang, Y.; Ma, R.; Zhang, X. Separation of tea polyphenol from Green Tea Leaves by a combined CATUFM-adsorption resin process. J. Food Eng. 2005, 67, 253-260.

23. Gao, Z.P.; Yu, Z.F.; Yue, T.L.; Quek, S.Y. Adsorption isotherm, thermodynamics and kinetics studies of polyphenols separation from kiwifruit juice using adsorbent resin. J. Food Eng. 2013, 116, 195-201.

24. Toledo, A.L.; Severo, J.B.; Souza, R.R.; Campos, E.S.; Santana, J.C.C.; Tambourgi, E.B. Purification by expanded bed adsorption and characterization of an $\alpha$-amylases FORILASE NTL ${ }^{\circledR}$ from A. niger. J. Chromatogr. B 2007, 846, 51-56.

25. Sun, L.; Guo, Y.; Fu, C.; Li, J.; Li, Z. Simultaneous separation and purification of total polyphenols, chlorogenic acid and phlorizin from thinned young apples. Food Chem. 2013, 136, 1022-1029.

26. Wan, P.; Sheng, Z.; Han, Q.; Zhao, Y.; Cheng, G.; Li, Y. Enrichment and purification of total flavonoids from Flos populi extracts with macroporous resins and evaluation of antioxidant activities in vitro. J. Chromatogr. B 2014, 945, 68-74.

27. Silva, E.M.; Pompeu, D.R.; Larondelle, Y.; Rogez, H. Optimisation of the adsorption of polyphenols from Inga edulis leaves on macroporous resins using an experimental design methodology. Sep. Purif. Technol. 2007, 53, 274-280.

28. Zhao, Z.; Zhang, J.; Chen, X.; Liu, X.; Li, J.; Zhang, W. Separation of tungsten and molybdenum using macroporous resin: Equilibrium adsorption for single and binary systems. Hydrometallurgy 2013, 140, 120-127.

29. Zhang, Y.; Liu, Z.; Li, Y.; Chi, R. Optimization of ionic liquid-based microwave-assisted extraction of isoflavones from Radix puerariae by response surface methodology. Sep. Purif. Technol. 2014, 129, 71-79.

30. Morelli, L.L.L.; Prado, M.A. Extraction optimization for antioxidant phenolic compounds in red grape jam using ultrasound with a response surface methodolog. Ultrason. Sonochem. 2012, 19, 1144-1149.

31. Sun, Y.; Xu, W.; Zhang, W.; Hu, Q.; Zeng, X. Optimizing the extraction of phenolic antioxidants from kudingcha made from Ilex kudingcha C.J. Tseng by using response surface methodology. Sep. Purif. Technol. 2011, 78, 311-320.

32. Kim, H.K.; Do, J.R.; Lim, T.S.; Akram, K.; Yoon, S.R.; Kwon, J.H. Optimisation of microwave-assisted extraction for functional properties of Vitis coignetiae extract by response surface methodology. J. Sci. Food Agric. 2012, 92, 1780-1785.

33. Zhao, S.; Zhang, D. A parametric study of supercritical carbon dioxide extraction of oil from Moringa oleifera seeds using a response surface methodology. Sep. Purif. Technol. 2013, 113, 9-17.

34. Liu, Y.; Liu, J.; Chen, X.; Liu, Y.; Di, D. Preparative separation and purification of lycopene from tomato skins extracts by macroporous adsorption resins. Food Chem. 2010, 123, 1027-1034.

35. He, Z.; Xia, W. Preparative separation and purification of phenolic compounds from Canarium album L. by macroporous resins. J. Sci. Food. Agric. 2008, 88, 493-498.

36. Nath, A.; Chattopadhyay, P.K. Optimization of oven toasting for improving crispness and other quality attributes of ready to eat potatosoy snack using response surface methodology. J. Food Eng. 2007, 80, 1282-1292. 
37. Rezaei, P.F.; Fouladdel, S.; Hassani, S.; Yousefbeyk, F.; Ghaffari, S.M.; Amin, G.; Azizi, E. Induction of apoptosis and cell cycle arrest by pericarp polyphenol-rich extract of Baneh in human colon carcinoma HT29 cells. Food Chem. Toxicol. 2012, 50, 1054-1059.

38. Roy, P.; Nigam, N.; George, J.; Srivastava, S.; Shukla, Y. Induction of apoptosis by tea polyphenols mediated through mitochondrial cell death pathway in mouse skin tumors. Cancer Biol. Ther. 2009, 8, 1281-1287.

39. Shen, X.; Zhang, Y.; Feng, Y.; Zhang, L.; Li, J.; Xie, Y.; Luo, X. Epigallocatechin-3-gallate inhibits cell growth, induces apoptosis and causes $\mathrm{S}$ phase arrest in hepatocellular carcinoma by suppressing the AKT pathway. Int. J. Oncol. 2014, 44, 791-796.

40. Fan, Z.L.; Wang, Z.Y.; Liu, J.R. Cold-field extracts exert different antioxidant and antiproliferative activities in vitro. Food Chem. 2011, 129, 402-407.

41. Vallverdú-Queralt, A.; Regueiro, J.; Martínez-Huélamo, M.; Alvarenga, J.F.R.; Leal, L.N.; Lamuela-Raventos, R.M. A comprehensive study on the phenolic profile of widely used culinary herbs and spices: Rosemary, thyme, oregano, cinnamon, cumin and bay. Food Chem. 2014, 154, 299-307.

42. Paepe, D.D.; Servaes, K.; Noten, B.; Diels, L.; Loose, M.D.; Droogenbroeck, B.V.; Voorspoels, S. An improved mass spectrometric method for identification and quantification of phenolic compounds in apple fruits. Food Chem. 2013, 136, 368-375.

43. Jaiswal. R.; Halabi, E.A.; Karar, M.G.E.; Kuhnert. N. Identification and characterisation of the phenolics of Ilex glabra L. Gray (Aquifoliaceae) leaves by liquid chromatography tandem mass spectrometry. Phytochemistry 2014, 106, 141-151.

44. Mahfoudhia, A.; Prencipe, F.P.; Mighri, Z.; Pellati. F. Metabolite profiling of polyphenols in the Tunisian plant Tamarixaphylla (L.) Karst. J. Pharm. Biomed. 2014, 99, 97-105.

45. Sulaiman, G.M.; Al Sammarrae, K.W.; Ad'hiah, A.H.; Zucchetti, M.; Frapolli, R.; Bello, Z.; Erba, E.; D'Incalci, M.; Bagnati, R. Chemical characterization of Iraqi propolis samples and assessing their antioxidant potentials. Food Chem. Toxicol. 2011, 49, 2415-2421.

46. Hilbert, G.; Temsamani, H.; Bordenave, L.; Pedrot, E.; Chaher, N.; Cluzet, S.; Delaunay, J.C.; Ollat, N.; Delrot, S.; Mérillon, J.M.; et al. Flavonol profiles in berries of wild Vitis accessions using liquid chromatography coupled to mass spectrometry and nuclear magnetic resonance spectrometry. Food Chem. 2015, 169, 49-58.

47. Regalado, E.L.; Tolle, S.; Pinoc, J.A.; Winterhalter, P.; Menendez, R.; Moralesd, A.R.; Rodríguez, J.L. Isolation and identification of phenolic compounds from rum aged in oak barrels by high-speed countercurrent chromatography/high-performance liquid chromatography-diode array detection-electrospray ionization mass spectrometry and screening for antioxidant activity. J. Chromatogr. A 2011, 1218, 7358-7364.

48. Jaiswal, R.; Müller, H.; Müller, A.; Karar, M.G.E.; Kuhnert, N. Identification and characterization of chlorogenic acids, chlorogenic acid glycosides and flavonoids from Lonicera henryi L. (Caprifoliaceae) leaves by LC-MS ${ }^{\mathrm{n}}$. Phytochemistry 2014, 108, 252-263.

49. Borrás-Linares, I.; Stojanović, Z.; Quirantes-Piné, R.; Arráez-Román, D.; Švarc-Gajić, J.; Fernández-Gutiérrez, A.; Segura-Carretero, A. Rosmarinus Officinalis Leaves as a Natural Source of Bioactive Compounds. Int. J. Mol. Sci. 2014, 15, 20585-20606. 
50. Zhao, C.F.; Li, S.; Li, S.J.; Song, G.H.; Yu, L.J.; Zhang, H. Extraction optimiza tion approach to improveaccessibility of functional fraction based on combination of total polyphenol, chroma tographic profiling and antioxidant activity evaluation: Pyracantha fortuneana fruit as an example. J. Funct. Foods 2013, 5, 715-728.

51. Iswaldi, I.; Arráez-Román, D.; Gómez-Caravaca, A.M.; Contreras, M.M.; Uberos, J.; Segura-Carretero, A.; Fernández-Gutiérrez, A. Identification of polyphenols and their metabolites in human urine after cranberry-syrup consumption. Food Chem. Toxicol. 2013, 55, 484-492.

52. Mari, A.; Tedesco, I.; Nappo, A.; Russo, G.L.; Malorni, A.; Carbone, V. Phenolic compound characterisation and antiproliferative activity of "Annurca" apple, a southern Italian cultivar. Food Chem. 2010, 123, 157-164.

53. Roseiroa, L.B.; Duartea, L.C; Oliveira, D.L.; Roque, R.; Bernardo-Gil, M.G.; Martins, A.I.; Sepúlveda, C.; Almeida, J.; Meireles, M.; Gírioa, F.M.; et al. Supercritical, ultrasound and conventional extracts from carob (Ceratonia siliqua L.) biomass: Effect on the phenolic profile and antiproliferative activity. Ind. Crop. Prod. 2013, 47, 132-138.

54. Corsi, L.; Avallone, R.; Cosenza, F.; Farina, F.; Baraldi, C.; Baraldi, M. Antiproliferative effects of Ceratonia siliqua L. on mouse hepatocellular carcinoma cell line. Fitoterapia 2002, 73, 674-684.

55. Bishayee, A.; Haznagy-Radnai, E.; Mbimba, T.; Sipos, P.; Morazzoni, P.; Darvesh, A.S.; Bhatia, D.; Hohmann, J. Anthocyanin-rich black currant extract suppresses the growth of human hepatocellular carcinoma cells. Nat. Prod. Commun. 2010, 5, 1613-1618.

56. Wu, L.C.; Hsu, H.W.; Chen, Y.C.; Chiu, C.C.; Lin, Y.I.; Ho, J.A.A. Antioxidant and antiproliferative activities of red pitaya. Food Chem. 2006, 95, 319-327.

57. Serra, A.T.; Matias, A.A.; Frade, R.F.M.; Duarte, R.O.; Feliciano, R.P.; Bronze, M.R.; Figueira, M.E.; de Carvalho, A.; Duarte, C.M.M. Characterization of traditional and exotic apple varieties from Portugal. Part 2-Antioxidant and antiproliferative activities. J. Funct. Foods 2010, 2, 46-53.

58. Fattahi, S.; Zabihi, E.; Abedian, Z.; Pourbagher, R.; Motevalizadeh, A.A.; Mostafazadeh, A.; Akhavan-Niaki, H. Total Phenolic and Flavonoid Contents of Aqueous Extract of Stinging Nettle and In Vitro Antiproliferative Effect on Hela and BT-474 Cell Lines. Int. J. Mol. Cell. Med. 2014, 3, 102-107.

59. Ghali, W.; Vaudry, D.; Jouenne, T.; Marzouki, M.N. Assessment of cyto-protective, antiproliferative and antioxidant potential of a medicinal plant Jatropha podagrica. Ind. Crop. Prod. 2013, 44, 111-118.

60. Faezizadeh, Z.; Mesbah-Namin, S.A.R.; Allameh, A. The effect of silymarin on telomerase activity in the human leukemia cell line K562. Planta Med. 2012, 78, 899-902.

Sample Availability: Not available.

(C) 2015 by the authors; licensee MDPI, Basel, Switzerland. This article is an open access article distributed under the terms and conditions of the Creative Commons Attribution license (http://creativecommons.org/licenses/by/4.0/). 